\title{
Michel Delon, Casanova, Histoire de sa vie
}

\section{Marisa Ferrarini}

\section{(2) OpenEdition}

\section{Journals}

\section{Edizione digitale}

URL: http://journals.openedition.org/studifrancesi/3741

DOI: 10.4000/studifrancesi.3741

ISSN: 2421-5856

\section{Editore}

Rosenberg \& Sellier

\section{Edizione cartacea}

Data di pubblicazione: 1 décembre 2012

Paginazione: 568-569

ISSN: 0039-2944

\section{Notizia bibliografica digitale}

Marisa Ferrarini, «Michel Delon, Casanova, Histoire de sa vie», Studi Francesi [Online], 168 (LVI | III) |

2012, online dal 30 novembre 2015, consultato il 06 mars 2021. URL: http://journals.openedition.org/ studifrancesi/3741; DOI: https://doi.org/10.4000/studifrancesi.3741

Questo documento è stato generato automaticamente il 6 mars 2021.

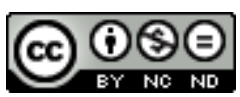

Studi Francesi è distribuita con Licenza Creative Commons Attribuzione - Non commerciale - Non opere derivate 4.0 Internazionale. 


\title{
Michel Delon, Casanova, Histoire de sa vie
}

\author{
Marisa Ferrarini
}

\section{NOTIZIA}

MICHEL Delon, Casanova, Histoire de sa vie, Paris, Gallimard (Collection «Découvertes»), 2011, pp. 128.

1 Questo libro è un ottimo compendio ai festeggiamenti che hanno seguito l'acquisto del manoscritto dell'Histoire de ma vie di Giacomo Casanova, nel febbraio 2010, da parte della BNF e sono culminati nella mostra Casanova, La passion de la liberté (Site François Mitterand) dal 15 novembre 2011 al 19 febbraio 2012, cui l'autore ha contribuito partecipando alla redazione del catalogo.

2 Giocando sul titolo delle 3700 pagine manoscritte che sono sopravvissute alle vicissitudini della storia, Michel Delon ha voluto mostrarci con l'Histoire de sa vie le mille sfaccettature di un personaggio troppo spesso ridotto al ruolo di grande amatore o di «prédateur sexuel» che accumula le sue conquiste, come recita la quarta di copertina. Stando all'Histoire de ma vie, le donne amate sarebbero 122, ma è un dato su cui Michel Delon volutamente sorvola, teso com'è ad evidenziare altri aspetti di Casanova. Nel primo capitolo («Un vénitien en Europe», pp. 10-29) ecco quindi apparire il viaggiatore che da Venezia si sposta a Costantinopoli, Parigi, Londra, San Pietroburgo. L'Europa è il campo in cui brillare o ridere, riuscire o rovinarsi. La sua vita è un'alternanza di favori principeschi e di miseria, di prigioni e di fughe, fino all'esilio finale come bibliotecario in un castello della Boemia.

3 Nel secondo capitolo («Théâtres», pp.30-43), è la volta dell'uomo di teatro. Figlio di attori, Casanova è soprattutto un istrione che sfrutta la propria oratoria. A Parigi, si serve dei suoi legami con la "Comédie italienne», s'impone sulla scena del mondo, ama delle attrici. A Venezia, è direttore di una compagnia teatrale, regista, attore. A Vienna, collabora con Da Ponte alla stesura del libretto del Don Giovanni di Mozart. 
4 Il terzo capitolo («Libertinages», pp. 44-59) mette in scena il libertino, pronto a ogni tipo di piacere. Quel che è proibito lo eccita: suore di clausura, vergini, fidanzate promesse ad altri, travestiti, fanciulle che potrebbero essere le proprie figlie. Ogni incontro è pretesto alla soddisfazione dei sensi, con tutte le conseguenze che ne derivano.

5 Il quinto capitolo («Savoirs», pp. 60-75) è dedicato all’uomo di scienza. Casanova vuole essere uomo universale. Esperto di letteratura, adatta l'Iliade, la cui traduzione è pubblicata a Venezia nel 1770. Versato nelle scienze, si appassiona per $\mathrm{i}$ «cabinets de curiosités» e i loro strumenti scientifici. I suoi manoscritti contengono lavori di algebra e numerologia. Sfrutta le sue conoscenze presso i potenti facendone sue vittime, tra martingale fruttuose e improbabili operazioni alchemiche.

Il quinto capitolo («Mémoires», pp. 76-97) concerne l'Histoire de ma vie. Bibliotecario a Dux, per fuggire alla noia dell'ambiente, Casanova si dedica alla stesura delle proprie memorie. S'inventa una lingua tra il francese e l'italiano, tra la presentazione aristocratica di sé (duelli, evasione dai Piombi) e la volontà di dire tutto (particolari intimi, scene erotiche).

7 Il libro si conclude con una serie di testimonianze e documenti, nell'ordine: «Portraits» (pp. 98-103), «Le polygraphe» (pp. 104-109), «Casanova censura» (pp. 110-111), «Une figure européenne» (pp. 112-113), «Un mythe cinématographique» (pp. 114-117).

8 Michel Delon ha utilizzato tutti gli strumenti iconografici per evocare questa figura di spicco dell'Europa moderna: attraverso le immagini del manoscritto dell'Histoire de ma vie; seguendo le sue tracce a Venezia nei quadri di Longhi o a Dux con dei disegni inediti; evocando l'erotismo del xvIII secolo con Boucher o Fragonard; attraverso i fotogrammi cinematografici. L'iconografia non fa che raddoppiare il piacere della lettura. 